\title{
Influence of substrate hydrophilicity on structural properties of supported lipid systems on graphene, graphene oxides, and silica
}

\author{
Supporting Information \\ Mariia Savenko ${ }^{1}$, Timothée Rivel ${ }^{1,2,3}$, Semen Yesylevskyy ${ }^{1,4}$, Christophe Ramseyer ${ }^{*}$ \\ ${ }^{1}$ Laboratoire Chrono Environnement UMR CNRS 6249, Université de Bourgogne Franche-Comté, 16 \\ route de Gray, 25030 Besançon Cedex, France. \\ ${ }^{2}$ CEITEC - Central European Institute of Technology, Masaryk University, Kamenice, Czech \\ Republic \\ ${ }^{3}$ National Centre for Biomolecular Research, Faculty of Science, Masaryk University, Kamenice, \\ Czech Republic \\ ${ }^{4}$ Department of Physics of Biological Systems, Institute of Physics of the National Academy of \\ Sciences of Ukraine, Prospect Nauky 46, 03028 Kyiv, Ukraine.
}




\section{- Description of the system}

Table S1. Lipid and water contents of the systems.

\begin{tabular}{lll}
\hline Setup & Number of lipids & $\mathrm{N}_{\text {water }} / \mathrm{N}_{\text {lipids }}$ \\
\hline Bicelle & 288 & $\sim 464$ \\
Bilayer - dry interface & 216 & $\sim 66$ \\
Bilayer - wet interface & 216 & $\sim 117$
\end{tabular}

Table S2. Sizes of the substrates ${ }^{1}$.

\begin{tabular}{|c|c|c|c|}
\hline Substrate & Setup & Length along the $\mathrm{x}$ axis, $\mathrm{nm}$ & $\begin{array}{l}\text { Length along the y axis, } \\
\mathrm{nm}\end{array}$ \\
\hline $\begin{array}{l}\text { Graphene- } \\
\text { based }\end{array}$ & Bicelle & 62.20 & 4.60 \\
\hline $\begin{array}{l}\text { Graphene- } \\
\text { based }\end{array}$ & Bilayer & 10.65 & 6.64 \\
\hline Silica & Bicelle & 62.12 & 4.60 \\
\hline Silica & Bilayer & 6.95 & 6.78 \\
\hline
\end{tabular}

- Errors on the density profiles
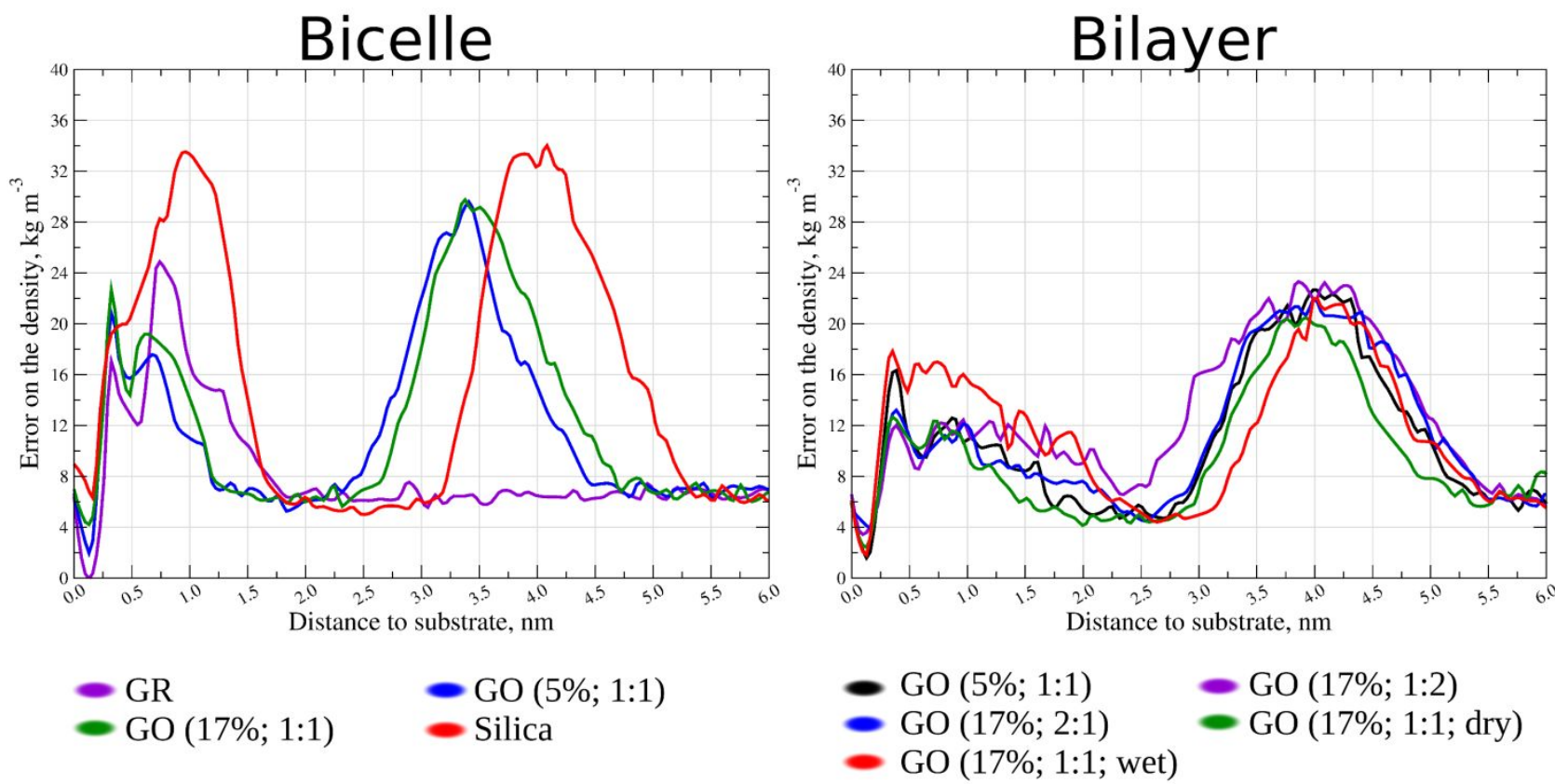

Figure S1. Errors on the density distribution of each system averaged over the last 50 ns of the trajectory for the different studied systems. The errors were computed using a Bayesian method considering the time autocorrelations.

1 The data related to the bilayer setup with silica are not shown in the present work. 